\title{
Erratum to: A retrospective study on the outcomes of posterior- only vertebral column resection in treating patients with severe isolated congenital kyphosis: more than 2 years follow-up in a single center
}

\author{
Shengru Wang ${ }^{1} \cdot$ Kahaer Aikenmu $^{2} \cdot$ Jianguo Zhang $^{1} \cdot$ Guixing Qiu $^{1}$. \\ Jianwei Guo ${ }^{1} \cdot$ Yanbin Zhang ${ }^{1} \cdot$ Xisheng Weng ${ }^{1}$
}

Received: 23 December 2015/Accepted: 11 January 2016/Published online: 28 January 2016

(C) Springer-Verlag Berlin Heidelberg 2016

\section{Erratum to: Eur Spine J}

DOI 10.1007/s00586-015-4344-9

There was an error in the article title.

The correct title is: A retrospective study on the outcomes of posterior-only vertebral column resection in treating patients with severe isolated congenital kyphosis: more than 2 years follow-up in a single center.

The online version of the original article can be found under doi:10.1007/s00586-015-4344-9.

Jianguo Zhang

jgzhang_pumch@yahoo.com

1 Department of Orthopedics of Peking Union Medical College Hospital, 1 Shuai Fu Yuan, Beijing 100730, P.R.China

2 Department of Spine Surgery of Traditional Chinese Hospital Affiliated to Xinjiang Medical University, Urumqi 830000, P.R.China 